Pustaka Karya: Jurnal Ilmiah Ilmu Perpustakaan dan Informasi

Vol. 9 No. 1, Juni 2021, Hal. 45-57

https://dx.doi.org/10.18592/pk.v9i1.5167

ISSN (p) : 2089-5216 | ISSN (e) : 2723-7699

\title{
Proses digitalisasi naskah kuno sebagai pelestarian informasi di Museum Bandar Cimanuk, Indramayu ${ }^{1}$ Ute Lies Siti Khadjah, ${ }^{2}$ Fitri Perdana, ${ }^{3}$ Desak Gde Delonix Regia Kirana Sarasvathi, ${ }^{4}$ Yunus Winoto \\ ${ }^{1234}$ Prodi Perpustakaan dan Sains Informasi, Fakultas Ilmu Komunikasi, Universitas Padjadjaran ${ }^{1} \mathrm{Jl}$. Raya Bandung Sumedang Km. 21 Jatinangor 45363 \\ e-mail: ${ }^{1}$ ute.lies@unpad.ac.id, ${ }^{2}$ fitri.perdana@unpad.ac.id, ${ }^{3}$ desak16001@mail.unpad.ac.id \\ 4yunus.winoto@unpad.ac.id
}

\begin{abstract}
Most of the ancient manuscripts found in Indramayu have been kept at the Bandar Cimanuk Museum, Indramayu. Most of the ancient manuscripts in the Bandar Cimanuk Museum, Indramayu, are written by hand or in the original form before printing. Digitalization is the process of transferring document media from printed, audio, and video forms. Equipment used in digitizing activities includes software and hardware. In digitizing ancient manuscripts, there are 2 stages that must be followed, pre-digitization and organizing. Using a qualitative methods and descriptive approach with a case study category. The survey data were descriptively analysed by using 3 steps there are reduction, presentation and conclutsin The result of the process of digitizing an ancient manuscript is an ancient manuscript in digital format. The results show that after the ancient manuscripts in the museum have been digitized, they can provide information according to the needs of the manuscript users and can preserve the information contained in the ancient manuscripts found at the Bandar Cimanuk Museum, Indramayu. Based on the results that have been found in digitizing ancient manuscripts at the Bandar Cimanuk Museum, Indramayu, there are a number of stages that must be carried out, namely the pre-digitalization stage and the organizing stage.
\end{abstract}

Keywords: ancient manuscripts; bandar cimanuk museum; digitalization; preservation

\begin{abstract}
ABSTRAK
Sebagian besar naskah kuno yang ditemukan di Indramayu telah disimpan di Museum Bandar Cimanuk, Indramayu. Naskah-naskah Kuno yang terdapat pada Museum Bandar Cimanuk, Indramayu, sebagian besar ditulis dengan tangan atau dalam bentuk asli sebelum dicetak. Digitalisasi merupakan proses alih media dokumen dari bentuk tercetak, audio, maupun video. Peralatan yang digunakan dalam melakukan kegiatan digitalisasi antara lain berupa perangkat lunak (Software) dan perangkat keras (Hardware). Dalam melakukan digitalisasi naskah kuno, terdapat 2 tahapan yang harus diikuti yakni tahapan pra digitalisasi dan pengorganisasian. Metode penelitian yang digunakan dalam penelitian ini adalah penelitian kualititatif. Jenis penelitian yang digunakan ialah pendekatan deskriptif dengan kategori studi kasus. Data analisis dalam penelitian ini menggunakan 3 tahapan yaitu reduksi, penyajian dan penarikan kesimpulan. Hasil dari proses digitalisasi naskah kuno adalah sebuah naskah kuno dalam format digital. Hasil penelitian menunjukkan bahwa setelah naskah-naskah kuno yang terdapat di museum tersebut telah didigitalisasi, dapat memberikan informasi sesuai dengan kebutuhan pengguna naskah serta dapat melestarikan informasi yang terkandung dalam naskah-naskah kuno yang terdapat pada Museum Bandar
\end{abstract}


Cimanuk, Indramayu. Berdasarkan hasil yang telah ditemukan dalam melakukan kegiatan digitalisasi naskah kuno di Museum Bandar Cimanuk, Indramayu, terdapat sejumlah tahapan yang harus dilakukan yaitu tahapan pradigitalisasi dan tahapan pengorganisasian.

Kata Kunci: digitalisasi; indramayu; museum bandar cimanuk; naskah kuno; indramayu; preservasi

\section{PENDAHULUAN}

Naskah kuno atau manuskrip dijelaskan Purnomo dalam Sukaesih merupakan dokumen dari berbagai peninggalan budaya yang ditulis dengan tangan tetapi lebih mengkhususkan kepada bentuk yang asli sebelum dicetak (Sukaesih dkk., 2016). Barried (Barried, 1985) menyatakan bahwa naskah kuno merupakan bentuk tulisan tangan yang ditulis pada kertas atau daun lontar yang berisi ungkapan pikiran dan perasaan sebagai hasil budaya bangsa pada masa lampau dan tidak ternilai harganya. Pada naskah kuno tertera nilai-nilai luhur yang disampaikan oleh nenek moyang secara turun-temurun, dari satu generasi ke generasi selanjutnya sehingga nilai tersebut akan tetap abadi.

Indonesia merupakan salah satu negara yang memiliki naskah kuno yang jumlahnya sangat banyak. Soebidio dalam Djamaris (Djamaris, 2002), menyatakan bahwa sebagian besar naskah kuno yang berada di Indonesia tertulis dalam huruf dan bahasa daerah. Jumlah naskah kuno yang terdapat di Indonesia hampir mencapai 10.000 naskah. Naskah-naskah tersebut tersebar di berbagai wilayah di Indonesia salah satunya di wilayah Indramayu, Jawa Barat. Indramayu merupakan salah satu wilayah yang memiliki jenis naskah kuno yang beragam.

Menurut Tarka Sutahardja (2019), sebagian besar jenis naskah kuno yang terdapat di Indramayu adalah hikayat dan manuskrip islam yang ditulis dalam Bahasa Jawa Kuno dan Bahasa Arab. Selama ini, sebagian besar dari naskah-naskah tersebut masih tersimpan dalam rumah pemilik naskah tersebut dan belum pernah dibaca oleh masyarakat lainnya, namun ada sejumlah naskah yang ia miliki, telah disimpan di Museum Bandar Cimanuk, Indramayu.

Naskah kuno merupakan tulisan peninggalan masa lampau yang mengandung informasi mengenai masa lampau yang tercipta dari latar belakang sosial budaya yang tidak sama dengan latar belakang sosial budaya masyarakat pada saat ini. Selain itu, naskah ini mengandung informasi yang berlimpah, tidak hanya sebatas pada kesusasteraan, tapi mencakup berbagai bidang seperti: agama, sejarah, hukum, adat-istiadat, dan sebagainya. Sehingga, sejarahwan dan para ahli diberbagai bidang sering menggunakan naskah kuno untuk menggali informasi dan data yang terkandung didalamnya.

Pada saat ini, dokumen naskah kuno memiliki permasalahan yang cukup serius, diantaranya adalah masih banyaknya naskah kuno yang tersimpan pada kalangan masyarakat atau perseorangan dan terancam mengalami kerusakan. Oleh karena itu, maka naskah kuno perlu dilestarikan pada setiap daerah, khususnya di daerah Indramayu, Jawa Barat. Upaya pelestarian naskah kuno dapat melalui penyimpanan di perpustakaan atau museum serta mengolah dan mengkaji ulang isi yang terkadung di dalamnya kemudian dimanfaatkan oleh masyarakat luas.

Menurut Dwi Putranto dan Jazimatul Husna (Putranto, 2015) dalam jurnal ilmu perpustakaan Universitas Diponegoro, faktor-faktor yang harus diperhatikan pada kegiatan digitalisasi koleksi adalah nilai bahan pustaka yang dimiliki (mempunyai nilai sejarah, nilai estetika, naskah kuno 
atau koleksi langka), jenis bahan pustaka (bahan pustaka cepat rusak), dan kebutuhan pengguna jasa perpustakaan (banyak digunakan oleh pemustaka).

Dalam melakukan seleksi digitalisasi, harus melihat banyak faktor apa saja yang perlu diperhitungkan ketika mendigitalkan bahan pustaka, seperti melihat kondisi fisik bahan pustaka tersebut, apakah nilai informasi yang terkandung berguna untuk pengguna atau instansi museum tersebut, apakah terdapat tenaga ahli yang profesional di bidang digitalisasi, apakah terdapat dana yang mencukupi, apakah bahan pustaka tersebut dilindungi oleh hak cipta, apakah sumber daya manusia (SDM) yang profesional dan berbagai pertimbangan yang sesuai dengan lembaga atau instansi yang terkait dalam proses kegiatan digitalisasi bahan pustaka. Demikian juga dalam kegiatan digitalisasi naskah kuno yang terdapat pada Museum Bandar Cimanuk, Indramayu.

Dalam penelitian ini akan dipaparkan mengenai pedoman standar teknis yang dipakai dalam kegiatan proses digitalisasi koleksi naskah kuno terutama pada tahapan seleksi atau pemilihan bahan pustaka yang akan melakukan proses digitalisasi di Museum Bandar Cimanuk, Indramayu. Tujuan penelitian ini adalah membuat digitalisasi sebagai upaya pelestarian naskah kuno yang terdapat pada Museum Bandar Cimanuk, Indramayu. Perangkat lunak (software), tidak hanya berfungsi sebagai alat untuk mendigitalisasi koleksi naskah kuno tersebut, akan tetapi juga untuk akses pada karakteristik yang diinginkan dan menjadi rancangan yang sesuai dalam menghasilkan sistem informasi naskah kuno yang terdapat pada Museum Bandar Cimanuk Indramayu.

\section{TINJAUAN PUSTAKA}

\section{A. DIGITALISASI}

Digitalisasi merupakan suatu proses yang kompleks, dan terdapat berbagai manfaat yang dapat diwujudkan dari berbagai jenis kegiatan digitalisasi. Menurut Lee (Lee, 2001) Alasan utama dari institusi untuk mendigitalisasikan koleksi museum adalah untuk meningkatkan akses. Bahkan dalam beberapa kasus, suatu bahan pustaka yang dipilih untuk digitalisasi adalah bahan pustaka yang tergolong langka atau unik. Dalam bentuk analog, bahan pustaka tersebut akan disimpan secara hati-hati dan hal itu akan menyebabkan bahan pustaka tersebut menjadi sesuatu yang spesial sehingga aksesnya terbatas.

Dengan adanya digitalisasi pada bahan pustaka tersebut, maka aksesnya akan menjadi lebih luas sehingga tidak terbatas pada kalangan tertentu saja. Selain itu yakni mengusahakan agar bahan pustaka asli tidak mengalami kerusakan, untuk menjaga nilai yang terkandung dalam bahan pustaka seperti nilai historis, bahan pustaka langka, kuno dan sebagainya. Jika suatu bahan pustaka dialih media dari bentuk analog menjadi bentuk digital dengan hasil yang berkualitas tinggi, maka dapat dikatakan kegiatan digitalisasi dapat memelihara bahan pustaka asli tersebut.

\section{B. NASKAH KUNO}

Naskah kuno berasal dari 2 kata yaitu “naskah” yang memiliki arti sebuah karangan yang ditulis menggunakan alat tulis dengan tangan atau karangan seseorang yang belum diterbitkan (Indonesia, 2011) dan kata "kuno" berarti lama atau dahulu kala (Indonesia, 2011). Dari pengertian tersebut, dapat disimpulkan bahwa naskah kuno merupakan sebuah teks yang ditulis pada masa lampau (Barried, 1985). Naskah kuno merupakan sebuah bentuk peninggalan budaya yang sampai saat ini masih dirasakan keberadaannya di Indonesia. Jumlah naskah kuno yang terdapat di Indonesia hampir mencapai 10.000 naskah. Naskah-naskah tersebut tersebar di 
berbagai wilayah di Indonesia seperti Pulau Jawa, Bali, Madura, Lombok, Bima, Aceh, Riau, Sumatera Utara, Sumatera Barat, Sumatera Selatan, dan Kalimantan Barat.

Naskah-naskah kuno yang ditemukan di beberapa daerah di Indonesia disajikan dalam berbagai macam baik dari segi bahan, bentuk, isi, bahasa, maupun aksara yang digunakannya. Adapun bahan yang digunakan dalam membuat naskah kuno menurut O.P Agawal dalam bukunya yang berjudul Preservation of Art Object (2012, 91-92) adalah sebagai berikut:

\section{Lembaran pohon berkulit putih tipis (bhoja patra)}

Lembaran pohon berkulit pohon tipis dapat dijumpai pada bagian bawah kulit pohon dari bawah pohon kulit putih yang ditemukan dalam ketinggian, kulit mati didalamnya memiliki lapisan yang tipis dan fleksibel seperti kertas. Lembaran dari pohon berkulit tipis itu dikenal dengan sebutan bhoja patra yang digunakan untuk menulis dengan tinta. Lembaran pohon tersebut dikenal dengan sebutan kulit pohon tetapi sebenarnya bagian pohon tersebut bukan kulit pohon melainkan bagian bawah kulit pohon yang dihapus dalam bentuk lembaran. Agar kulit pohon tersebut dapat digunakan untuk menulis, kulit pohon tersebut perlahan-lahan dikeringkan.

Lembaran pohon tersebut telah siap yang kemudian tersusun oleh beberapa lapisan yang tergabung dalam getah alami dan ikatan atau simpulan kayu. Naskah itu kemudian disimpan diantara dua kayu penutup,dikelilingi oleh tali ( dibundel),kemudian dilewati lembaran-lembaran kayu lainnya dan diikat menjadi satu. Penyimpanan dalam kurun waktu yang lama dapat menyebabkan lembaran pohon tersebut menjadi lemah dan rapuh, dikarenakan kekuatan pada unsur lapisan pada lembaran pohon hilang antara lapisan satu dengan lapisan yang lainnya, sehingga membutuhkan pemeriksaan dari seorang ahli serta perawatan didalam konservasi laboratorium.

Lembaran pohon tersebut terkadang melekat satu sama lain jika disimpan didalam keadaan lembab untuk waktu yang lama. Setiap daun naskah tersebut seharusnya diperiksa secara periodik kemudian membersihkannya dengan sikat yang halus dan dikeringkan. Lembaran pohon tersebut seperti kertas yang juga dapat terkena noda. Noda yang terdapat pada lembaran pohon harus ditangani secara hati-hati dikarenakan noda yang terdapat pada lembaran pohon tersebut tidak dapat dihapus dan lembaran pohon bersifat rapuh secara alamiah.

Untuk melindungi lembaran kulit tersebut dibutuhkan ventilasi pada ruangan penyimpanannya, fumigasi secara berkala dan dibutuhkan kebersihan didalamnya. Naskah dari daun pohon tersebut seharusnya selalu disimpan diantara papan kertas yang kuat, setelah dibungkus atau dikemas didalam kertas halus yang bersih. Papan kertas itu seharusnya sedikit lebih luas dibandingkan dengan lembaran naskah sampai pada bundelan naskah dapat dibungkus dengan bundelan kain (Agrawal dkk., 1997).

\section{Naskah Daun Palem}

Nipah dan lontar merupakan pohon dengan suku (famili) yang sama yaitu Arecaceae atau suku palem. Nipah merupakan semacam pohon yang tumbuh di iklim hangat,berdaun lebar, dan berserat tipis. Sedangkan lontar merupakan jenis daun siwalan yang dikeringkan dan dipakai sebagai naskah atau kerajinan. Sebelum adanya sebuah kertas, daun palem adalah bahan untuk menulis yang paling penting hampir diseluruh bagian negara asia selatan dan tenggara. Daun palem yang telah dikeringkan, diikat didalam air selama beberapa jam, kemudian dikeringkan 
kembali. Daun tersebut dipotong berdasarkan ukuran yang dibutuhkan. Daun palem memiliki bentuk yang panjang namun daun ini memiliki bentuk yang kurang lebar, terkadang dua atau lebih daun dijahit bersamaan untuk menjadikan permukaan yang lebih luas untuk menulis.

Cara menulis di daun palem, salah satu logam jarum piringan hitam runcing harus dibuat untuk memotong serat dan ilustrasi daun. Naskah daun pale mini disimpan diantara papan yang terbuat dari kayu pada umumnya, dan terkadang papan tersebut dihiasi ukiran atau lukisan. Dalam proses penyimpanan yang lana, daun palem akan menjadi rapuh dan lebih mudah rusak. Keadaan ini terjadi ketika keadaan atmosfer atau udara sangat kering. Daun palem yang sudah rapuh tadi biasanya disimpan dalam kotak kecil sebagai bentuk penanganannya. Jika daun tersebut sudah terlalu lemah dan tidak memiliki kekuatan lagi, maka daun tersebut harus segera dikonsultasikan dan ditangani oleh ahlli dan dibawa kelaboratorium.

Bagian yang paling halus pada daun palem berada dibagian pinggir daun. Pinggir daun tersebut mudah cepat rapuh dan rusak. Oleh karena itu, daun-daun tersebut harus selalu disimpan diantara dua buah papan kayu agar sedikit lebih lebar dari ukuran daun tersebut seperti yang dilakukan pada masa lampau. Hal lain yang dilakukan untuk mencegah dan menangani terjadi kerusakan pada daun sebaiknya memiliki microfilm dan microchif dari naskah tersebut. Serangan serangga merupakan kerusakan yang paling berat pada daun palem, dan pada umumnya sering terjadi pada daun palem dibandingkan dengan kertas. Fumigasi dengan menggunakan segi air dan penggunaan insektisida adalah solusi yang paling efektif untuk penanganannya, lemari dan rakrak yamg harus digunakan sebagai tempat penyimpanam naskah daun palem harus memiliki 1\% lindane sebagai solusi dari pencegahan serangga.

Isi kandungan dalam teks naskah kuno di Indonesia cukup bervariasi. Pada umumnya, isi kandungan yang terdapat pada naskah kuno mencakup berbagai aspek yang terdapat di dalam kehidupan manusia seperti masalah sosial, politik, ekonomi, agama, kebudayaan, bahasa, dan sastra. Adanya variasi budaya pada naskah kuno tersebut dipengaruhi oleh berbagai hal yakni konteks budaya pada setiap daerah, tujuan dari pembuatan naskah, dan semangat pada zaman naskah kuno tersebut dibuat.

Naskah-naskah kuno yang ada di Indonesia terbagi kedalam beberapa bentuk seperti prosa, prosa berirama, puisi, dan drama (Djamaris, 2002). Sedangkan bahasa yang digunakan dalam naskah kuno, bergantung pada tempat asal naskah kuno tersebut ditemukan, seperti bahasa Jawa, Sunda, Melayu, Aceh, Batak, Minangkabau, Bugis, Makassar, Banjar, dan Wolio. Hal yang sama juga terjadi pada aksara yang digunakan dalam penulisan naskah kuno di Nusantara. Aksara yang digunakan dalam penulisan naskah kuno antara lain aksara Bali, Jawa, Sunda, Jawi (ArabMelayu), Pegon, Bugis, Makasar, Karo, Mandaling, Rejang, Toba, Lampung, dan Kerinci.

\section{METODE PENELITIAN}

Metode penelitian yang digunakan dalam penelitian ini adalah penelitian kualititatif. Jenis penelitian yang digunakan ialah pendekatan deskriptif dengan kategori studi kasus. Dengan demikian dapat disimpulkan bahwa metode penelitian ini dapat digunakan untuk memperoleh gambaran yang lebih jelas mengenai pedoman standar teknis seleksi dalam proses digitalisasi koleksi di Museum Bandar Cimanuk, Indramayu. Subjek dari penelitian ini adalah naskah kuno yang terdapat pada Museum Bandar Cimanuk, Indramayu. 
Penelitian dilaksanakan pada tanggal 30 September 2019 sampai dengan 22 Januari 2020 dan lokasi penelitian terletak pada Museum Bandar Cimanuk, Indramayu. Teknik Pengumpulan data dilakukan dengan cara wawancara untuk menggali lebih lanjut mengenai informasi yang terkandung dalam naskah kuno yang terdapat dalam Museum Bandar Cimanuk, Indramayu. Selanjutnya dokumentasi yang berfungsi untuk merubah naskah kuno tercetak kedalam bentuk digitaln serta pengamatan terhadap naskah yang ada di Museum Bandar Cimanuk, Indramayu. Untuk menganalisis data dilakukan memalui tiga alir yaitu reduksi, penyajian dan penarikan kesimpulan.

\section{HASIL DAN PEMBAHASAN}

\section{A. KEGIATAN DIGITALISASI NASKAH KUNO DI MUSEUM BANDAR CIMANUK, INDRAMAYU}

Adapun prioritas yang ditetapkan oleh Museum Bandar Cimanuk, Indramayu dalam hal digitalisasi tergantung dari faktor-faktor setiap naskah kuno yang dimiliki oleh museum tersebut mempunyai nilai sejarah, nilai akademis, dan nilai estetika. Nilai-nilai yang terkandung dalam naskah kuno yang terdapat di Museum Bandar Cimanuk, Indramayu sampai saat ini dapat diterapkan oleh masyarakat luas, khususnya masyarakat Indramayu, Jawa Barat Oleh karena itu, sudah selayaknya naskah kuno yang terdapat pada museum tersebut dilestarikan agar nilai-nilai yang terkandung dalam naskah kuno dapat dimanfaatkan dan diwariskan ke generasi selanjutnya, sehingga nilai yang terkandung dalam naskah kuno tersebut akan tetap abadi sepanjang masa.

Sebagian besar naskah kuno yang terbuat dari bahan kertas daluang dan erofah mudah rusak sehingga perlu dilestarikan bentuk fisik dari naskah kuno tersebut. Oleh karena itu, sudah selayaknya koleksi naskah kuno yang terdapat di Museum Bandar Cimanuk, Indramayu dilestarikan dengan cara membuat kedalam bentuk lain, yaitu mendigitalisasi naskah kuno tersebut, sehingga informasi yang terdapat dalam naskah kuno tersebut dapat dimanfaatkan oleh masyarakat luas. Salah satu prioritas dalam melakukan kegiatan reproduksi adalah penggunaan jasa museum terhadap bahan pustaka yang masih tergolong tinggi. Selain itu, naskah kuno yang terdapat di museum tersebut masih sering digunakan sebagai sarana sumber informasi oleh masyarakat luas, khususnya masyarakat Kabupaten Indramayu. Oleh karena itu, perlu dibuatkan dalam bentuk media lain seperti digitalisasi dalam bentuk CD atau E-Book.

\section{Kegiatan seleksi koleksi naskah kuno yang akan didigitalisasi di museum bandar cimanuk, indramayu}

Sampai saat ini, Museum Bandar Cimanuk, Indramayu belum memiliki kriteria seleksi yang baku secara tertulis, tetapi dalam menentukan koleksi bahan pustaka yang akan dipilih untuk didigitalisasikan. Untuk menyeleksi naskah kuno yang akan didigitalisasikan di Museum Bandar Cimanuk terdapat beberapa kriteria yang perlu dipertimbangkan dari koleksi buku-buku tua atau langka yang akan diprioritaskan untuk didigitalkan, adapun kriteria tersebut adalah a) konten (isi) dari naskah kuno di Museum Bandar Cimanuk, Indramayu mengandung nilai hakikat diri sejati, hikayat, ajaran tasawuf, dan peperangan Pramakawi dan Jaya Binangun.

Informasi ini sangat dibutuhkan sampai saat ini baik oleh peneliti maupun oleh masyarakat luas sebgaia perbandingan dengan situasi pada saat ini. Koleksi jenis ini dipilih dikarenakan sebagian besar usia koleksi naskah kuno yang terdapat di museum tersebut sudah sangat tua yaitu sekitar abad ke 18 M; b) kondisi naskah-naskah kuno yang di reproduksi di Museum Bandar Cimanuk, 
Indramayu sebsgian besar tidak terawat, halamannya robek, jamuran, berdebu, dan tulisan yang terdapat pada naskah kuno tersebut tidak dapat dibaca. Hal itu disebabkan karena tulisan tersebut ditulis dengan tinta yang sangat tipis.

\section{Alat-alat yang digunakan dalam proses digitalisasi naskah kuno di museum bandar cimanuk, indramayu}

Dalam melakukan proses digitalisasi, dibutuhkan sejumlah alat yang berupa perangkat keras (Hardware) dan perangkat lunak (Software). Adapun alat-alat yang digunakan dalam proses digitalisasi antara lain sebagai berikut:

a) Perangkat Keras

1) Laptop atau komputer jinjing merupakan komputer bergerak yang berukuran relatif kecil dan ringan, yang memiliki berat berkisar dari 1-6 kg, tergantung padukuran, bahan, dan spesifikasi laptop tersebut. Sumber daya laptop berasal dari baterai atau adaptor A/C yang dapat digunakan untuk mengisi ulang baterai dan menyalakan laptop itu sendiri. Baterai laptop pada umumnya dapat bertahan sekitar 2 hingga 6 jam sebelum akhirnya habis, tergantung dari cara pemakaian, spesifikasi, dan ukuran baterai. Pada umumnya, laptop memiliki fungsi yang sama dengan komputer desktop (desktop computers).

Komponen yang terdapat di dalamnya sama persis dengan komponen pada desktop, hanya saja ukuran laptop diperkecil, dijadikan lebih ringan, lebih tidak panas, dan lebih hemat daya. Dalam kegiatan digitalisasi naskah kuno, laptop berfungsi sebagai alat untuk memfoto naskah dan sebagai alat untuk mempermudah penyimpanan hasil digitalisasi naskah kuno tersebut. Laptop yang digunakan untuk digitalisasi naskah kuno tersebut memiliki konfigurasi minimum: Prosesor Pentium 4 kelas berjalan pada 2,0 GHz atau lebih tinggi $512 \mathrm{MB}$, memori minimum $160 \mathrm{~GB}$, Hard drive 18 "atau monitor 128 MB kartu video yang lebih besar, CD-RW dan atau drive optik DVD-R.

2) Kamera digital merupakan kamera yang tidak bergantung pada film negative (klise). Pada kamera digital, peran film negatif diambil oleh sebuah chip berbentuk kartu kecil yang berfungsi untuk menyimpan hasil pemotretan. Ada dua tipe cip pada kamera digital yaitu CCD (Charge Coupled Device) dan CMOS (Complementary Metal Oxide Semiconductor). Cip berfungsi untuk menangkap gambar fotografi dalam bentuk digital pada disket kecil yang dimasukkan ke dalam kamera atau pada chip memori flash. Kelebihan dari kamera ini adalah hasil pemotretan dapat langsung dilihat pada layar monitor yang terletak di bagian belakang kamera. Jika gambar yang diambil tidak sesuai dengan yang diinginkan, bisa langsung dihapus.

Selain itu, kamera digital ini juga dilengkapi dengan fasilitas zoom yaitu pengaturan perbesaran objek yang akan diambil tanpa harus mendekatkan kamera ke objek, serta pengaturan terang gelap lampu blitz. Kemampuan kamera digital diukur dalam megapixel, yaitu kemampuan kamera untuk menangkap objek. Makin besarnya angka, berarti makin detaik gambar yang dihasilkan sehingga kualitas gambar makin tajam. Dalam digitalisasi naskah kuno, kamera digital digunakan untuk memfoto naskah kuno tersebut. Kamera digital yang digunakan dalam digitalisasi naskah kuno ini adalah kamera Canon EOS Utility 3000d dengan spesifikasi sensor CMOS APS-C 18 megapiksel dan prosesor gambar DIGIC 4 +, AF 9 titik dengan 1 titik AF tipe silang tengah, dan memiliki ISO sebesar 100-6400 Standar (dapat diperluas hingga 12800). 
3) Tripod merupakan penyangga yang memiliki tiga kaki dan berfungsi untuk membantu agar badan kamera bisa berdiri dengan tegak. Tripod digunakan untuk membantu kelelahan fotografer dalam mengambil gambar dan mengurangi noise yang ditimbulkan oleh guncangan tangan fotografer. Tripod biasanya dipakai apabila fotografer menggunakan kecepatan rana di angka 30 atau lebih lambat atau menggunakan lensa kamera dengan focal length lebih dari $200 \mathrm{~mm}$.

4) Lampu lighting soft box merupakan jenis lampu lighting yang terbuat dari bahan transparan yang berguna untuk menghaluskan cahaya pada hasil foto tersebut. Pada umumnya, sebuah lampu lighting softbox memiliki 1 atau 2 buah lapisan bahan transparan. Lampu ini memiliki berbagai macam bentuk, salah satunya adalah berbentuk persegi panjang. Dalam melakukan reproduksi naskah kuno, lampu lighting digunakan sebagai alat bantu penerangan dalam proses foto naskah-naskah kuno tersebut.

b) Perangkat lunak

1) PDF (Portable Document Format) atau Format Dokumen Portabel merupakan format file standar industri untuk berbagi dokumen. Format file yang dikembangkan oleh Adobe Systems ini, dapat menggandakan berbagai macam jenis file seperti foto, file teks, halaman web, desain grafis, halaman pengolah kata, atau screenshot. Format ini memberikan solusi cepat dan mudah untuk melihat dan mengunduh file online. Perangkat lunak ini tersedia secara gratis di internet. Dalam kegiatan digitalisasi dan reproduksi naskah kuno, perangkat lunak ini digunakan untuk menyimpan hasil digitalisasi naskah kuno yang telah melakukan proses editing pada Microsoft Word.

2) Perangkat lunak JPG atau Joint Photographic Experts Group (JPEG) merupakan skema kompresi file bitmap yang dijadikan standar untuk para fotografer profesional. Kompresi JPG digunakan untuk menyimpan data yang besar di media penyimpanan yang terbatas, tidak untuk digunakan untuk memanipulasi hasil foto. Format JPG telah menjadi ukuran standar pada internet, karena format file ini dapat dikonversi menjadi ukuran yang lebih kecil. Data JPG dapat dikonversi dengan rasio perbandingan 2:1 sampai paling tinggi 100:1, bergantung pada kebutuhan. File JPG mempunyai teknik kompresi yang menyebabkan kualitas foto atau gambar menjadi menurun (lossy compression).

Oleh karena itu, file JPG cocok digunakan untuk menyimpan gambar yang memiliki banyak warna, seperti foto wajah dan pemandangan dan tidak cocok digunakan untuk gambar yang hanya memiliki sedikit warna seperti kartun atau komik. Dalam kegiatan digitalisasi naskah kuno, perangkat lunak JPG digunakan untuk menyimpan hasil foto naskah kuno yang telah didigitalisasi. Selain perangkat lunak dan perangkat keras, kegiatan digitalisasi naskah kuno di museum ini memerlukan alat bantu lain seperti sejumlah kartu atau kertas yang digunakan untuk menahan kertas agar tidak tergeser ketika melakukan proses foto dan kain hitam yang digunakan sebagai alas untuk menyimpan naskah di meja ketika melakukan proses digitalisasi.

\section{Proses digitalisasi koleksi naskah kuno}

Dalam memproses digitalisasi naskah kuno, ada 2 tahapan yang harus diikuti yaitu melalui tahapan perencanaan dan tahapan pengorganisasian. Dalam melakukan kegiatan digitalisasi, terdapat beberapa hal yang perlu diperhatikan yaitu menyesuaikan kondisi naskah kuno yang yang ada, termasuk mengidentifikasi sejauh mana kebutuhan dan kemampuan dalam melaksanakannya juga perlu dijabarkan berikutnya yaitu dengan merumuskan kebutuhan 
perangkat keras dan lunak (hardware dan software), serta kebutuhan sumber daya manusia, dalam menyusun waktu pelaksanaan, dan dukungan dana. Tahapannya dilakukan sebagai berikut:

a) Pra-digitalisasi

Pra-digitalisasi merupakan proses kerja fisik berupa kegiatan mengumpulkan, memilah, dan menata kembali dokumen dengan mekanisme sebagai berikut 1) menseleksi dokumen naskah kuno yang mengalami kerusakan cukup signifikan. Dalam melakukan digitalisasi naskah kuno, pihak museum menseleksi naskah kuno yang memiliki kerusakan yang cukup signifikan. Berdasarkan hasil pengamatan langsung yang dilakukan oleh peneliti, sebagian naskah kuno yang terdapat di museum tersebut mengalami kerusakan yang cukup signifikan seperti halamannya robek, jamuran, berdebu, dan tulisan yang sangat tipis sehingga hampir tidak terbaca; 2) memastikan dokumen yang akan di digitalisasi tidak mengalami duplikasi (satu judul satu eksemplar); 3) agar kegiatan digitalisasi naskah kuno di museum bandar cimanuk, indramayu dapat berjalan optimal, pihak museum memastikan dokumen naskah kuno yang akan didigitalisasi tidak mengalami duplikasi (satu judul satu eksemplar).

Untuk memastikan keadaan tersebut, pihak museum mengecek satu-persatu naskah-naskah yang akan di digitalisasi; 4) melakukan pembongkaran dengan baik dan tidak merusak dokumen; 5) naskah kuno di museum tersebut terdapat beberapa yang halamannya saling menempel antara satu halaman dengan halaman yang lainnya. Oleh karena itu, sebelum dilakukan digitalisaso, sejumlah naskah harus melewati proses pembongkaran dengan cara melepaskan halaman naskah tersebut satu persatu secara perlahan; 6) memeriksa kembali kelengkapan dokumen sebelum melakukan kegiatan digitalisasi; 7) sebelum melakukan kegiatan digitalisasi, kelengkapan isi dari naskah tersebut diperiksa satu-persatu agar tidak tercecer pada saat melakukan proses digitalisasi dan reproduksi. Kelengkapan dokumen yang diperiksa antara lain cover dan jumlah halaman yang terdapat pada naskah-naskah kuno yang akan di digitalisasi. Jumlah halaman pada naskah kuno yang didigitalisasi oleh peneliti lengkap, tetapi ada beberapa halaman yang robek.

\section{b) Pengorganiasian}

Pengorganisasian merupakan proses kerja lanjutan dari kegiatan digitalisasi naskah kuno. adapun kegiatan pengorganisasian yang dilakukan di museum tersebut adalah kegiatan digitalisasi, dan editing. adapun mekanisme kegiatan pengorganisasian di museum tersebut adalah sebagai berikut: 1) mempersiapkan peralatan yang digunakan dalam kegiatan digitalisasi naskah kuno. sebelum melakukan kegiatan digitalisasi naskah kuno, peneliti harus mempersiapkan alat-alat yang digunakan untuk melakukan kegiatan digitalisasi di museum bandar cimanuk indramayu tersebut. alat-alat yang digunakan dalam melakukan digitalisasi naskah kuno tersebut antara lain adalah kamera digital canon ios utility, laptop, meja yang sudah beralaskan kain hitam, tripod, dan lampu flash berwarna putih.

2) Memeriksa kelengkapan dokumen naskah kuno sebelum melakukan digitalisasi. setelah semua alat yang dibutuhkan telah dipersiapkan, langkah selanjutnya adalah memeriksa kelengkapan dokumen naskah kuno tersebut. kelengkapan dokumen naskah kuno yang diperiksa antara lain seperti cover, serta jumlah halaman dan kejelasan tulisan atau huruf pada naskah kuno tersebut; 3) memeriksa dan memperbaiki dokumen naskah kuno yang mengalami kerusakan. naskah kuno yang didigitalisasi sudah berumur ratuan tahun dan banyak bagian dari naskah kuno tersebut mengalami kerusakan yang cukup signifikan seperti robek dan berlubang. oleh karena 
itu, pihak museum melakukan pemeriksaan dan perbaikan terhadap dokumen naskah kuno tersebut. adapun cara yang dilakukan untuk memperbaikinya adalah dengan membersihkan halaman naskah menggunakan kuas kecil yang sangat halus dan lembut sehingga huruf-huruf jawa kuno dan arab pegon dapat dibaca dengan jelas. selain itu, halaman naskah kuno yang terlepas disatukan dengan cara menempelkan kembali antara satu kertas dengan kertas yang lainnya menggunakan lem kertas.

c) Menata dokumen naskah kuno yang akan dipindai di atas meja

Sebelum dilakukan proses digitalisasi, dokumen naskah kuno ditata terlebih dahulu diatas meja yang sudah dialasi kain hitam atau kain putih. Naskah kuno tersebut diletakkan persis di depan lensa kamera dan agar tidak berubah posisinya maka naskah kuno tersebut disangga dengan menggunakan sejumlah kartu atau kertas. Dengan demikian, diharapkan mendapatkan hasil foto naskah kuno yang tampak jernih dan dapat dibaca dengan jelas.

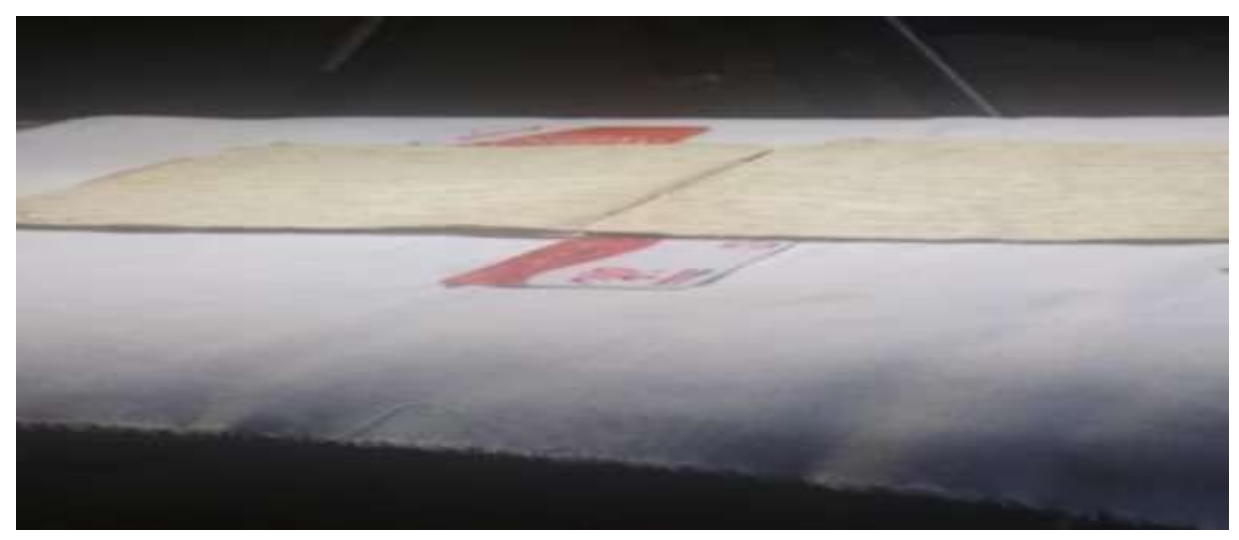

Gambar 1 dokumen naskah Kuno yang siap dipindai

d) Memindai dokumen naskah kuno dari halaman depan hingga akhir

Dalam memindai dokumen naskah kuno tersebut, ada sejumlah tahapan yang harus diikuti. Adapun tahapan-tahapan tersebut adalah sebagai berikut: dokumen naskah kuno tersebut dibuka satu persatu setiap halaman dengan hati-hati. Setelah halaman buku naskah tersebut dibuka, lalu klik tombol kamera yang berada pada layar laptop yang digunakan dalam proses pemindaian naskah tersebut. Setelah selesai dipindai, selanjutnya buka halaman naskah kuno berikutnya secara perlahan dan lakukan tahapan yang telah disebutkan secara berulang hingga semua halaman yang terdapat pada naskah kuno tersebut selesai dipindai.

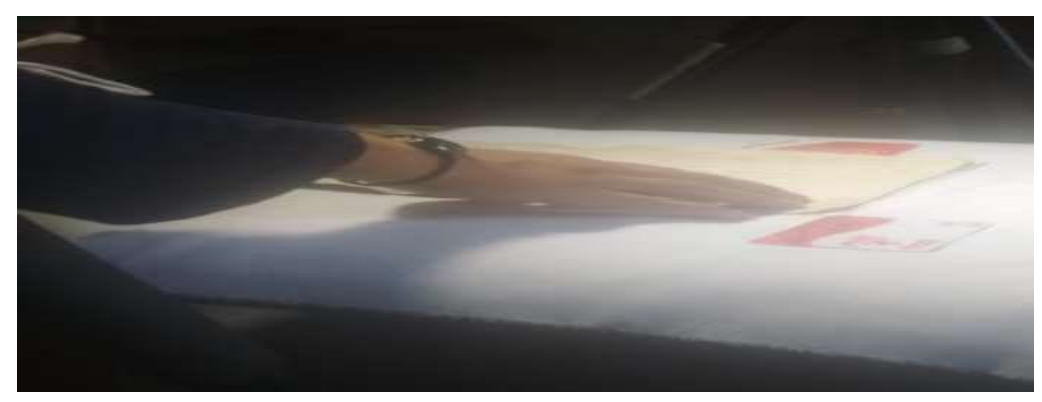

Gambar 2 proses pemindaian dilakukan pada setiap halaman 
e) Menyimpan file elektronik dalam bentuk jpg

Setelah melakukan proses pemindaian, file tersebut disimpan dalam bentuk JPG agar memudahkan dalam proses editing. Dalam menyimpan file tersebut dinamai sesuai nama dan halaman naskah kuno tersebut.

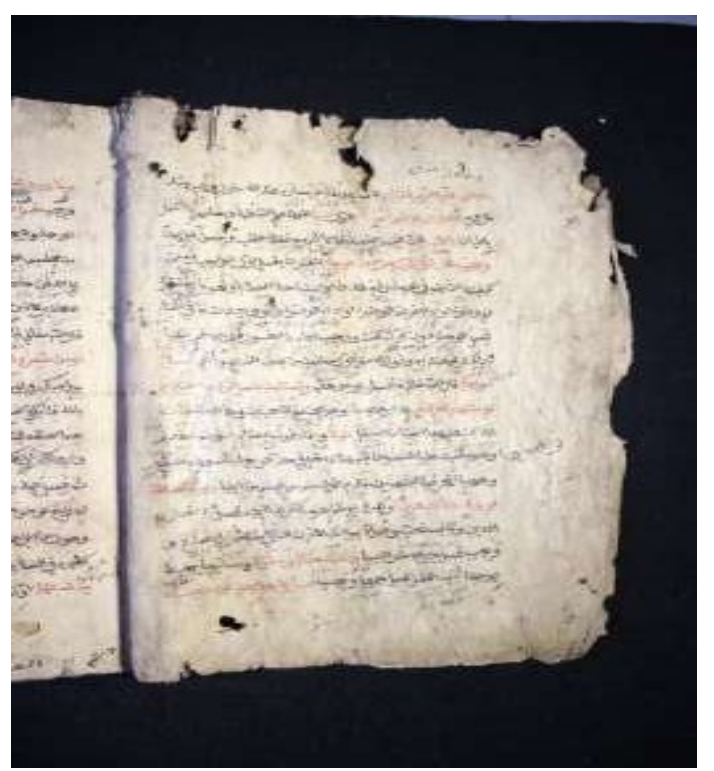

Gambar 3 Hasil digitalisasi naskah kuno yang telah disimpan ke dalam bentuk JPG

f) Memeriksa dan mencocokan dengan hasil digitalisasi dokumen asli

Hasil foto diperiksa dan dicocokan kembali terlebih dahulu dengan dokumen aslinya, agar dokumen hasil proses digitalisasi sesuai dengan aslinya dan sesuai dengan harapan.

\section{4. $\quad$ Editing}

Setelah melakukan proses digitalisasi, selanjutnya dokumen naskah kuno tersebut diedit melalui proses editing, agar hasil foto tersebut mudah untuk direproduksi dan sesuai dengan harapan. Editing adalah suatu kegiatan yang dilakukan untuk mengubah tampilan yang sebenarnya menjadi foto seperti yang diinginkan dengan cara menambahkan efek-efek tertentu atau dengan memadukan beberapa foto menjadi 1 foto. Dalam melakukan proses editing, ada sejumlah tahapan yang harus diikuti. Tahapan-tahapan dalam proses editing adalah sebagai berikut:

a) Membersihkan noda pada hasil foto naskah kuno dengan menggunakan perangkat lunak Adobe PhotoShop. Sebelum melakukan proses editing, noda pada hasil foto naskah kuno tersebut nampak dibersihkan terlebih dahulu, agar hasil dari foto naskah kuno tersebut jelas dan layak untuk direproduksi. Adapun tahapan-tahapan dalam membersihkan noda pada hasil foto naskah kuno tersebut adalah sebagai berikut: 1) uka aplikasi Adobe Photoshop dan masukkan hasil foto naskah kuno tersebut ke dalam aplikasi dengan cara klik File lalu klik Open dan pilihlah foto naskah kuno yang akan dibersihkan; 2) setelah itu, klik ikon "Properties" kemudian klik "Lasso Tool” dan seleksi noda pada naskah kuno yang akan dibersihkan tersebut 3) setelah menyeleksi noda yang akan dibersihkan, lalu klik kanan pada noda yang telah diseleksi tersebut, lalu klik pilihan "Fill”; 4) setelah diklik, maka muncul pilihan yakni Contents, dan Bleeding. Pada pilihan Contents, klik pilihan Content Aware dan pada pilihan Bleeding terdapat beberapa sub menu yakni Wide dan Opacity. Pada bagian sub menu Wide, klik pilihan Normal dan pada 
sub menu Opacity, klik pilihan 100\%. Setelah semua pilihan tersebut di klik, kemudian klik OK; 5) Tahapan-tahapan tersebut dilakukan secara berulang hingga noda pada semua halaman yang terdapat pada foto naskah kuno tersebut selesai dibersihkan secara keseluruhan.

b) Memindahkan file foto naskah kuno tersebut ke dalam Microsoft Word. Adapun tahapannya adalah sebagai berikut: 1) atur ukuran kertas kedalam ukuran A-5 dengan cara klik layout, kemudian klik size, lalu klik pilihan A-5; 2) margin kertas diatur dengan cara klik Layout, lalu klik Custom Margins, lalu margin tersebut diatur dengan Top :1,1 cm, Left: 1,0 cm, Bottom: 0,67 cm, dan Right: 1,34 cm, kemudian klik OK; 3) potong (crop) foto pada bagian backgroundnya, sehingga tampak lebih rapi dan layak untuk direproduksi; 4) simpan file naskah kuno ke dalam bentuk PDF dengan tujuan agar filenya hasil digitalisasi tersebut tidak berubah.

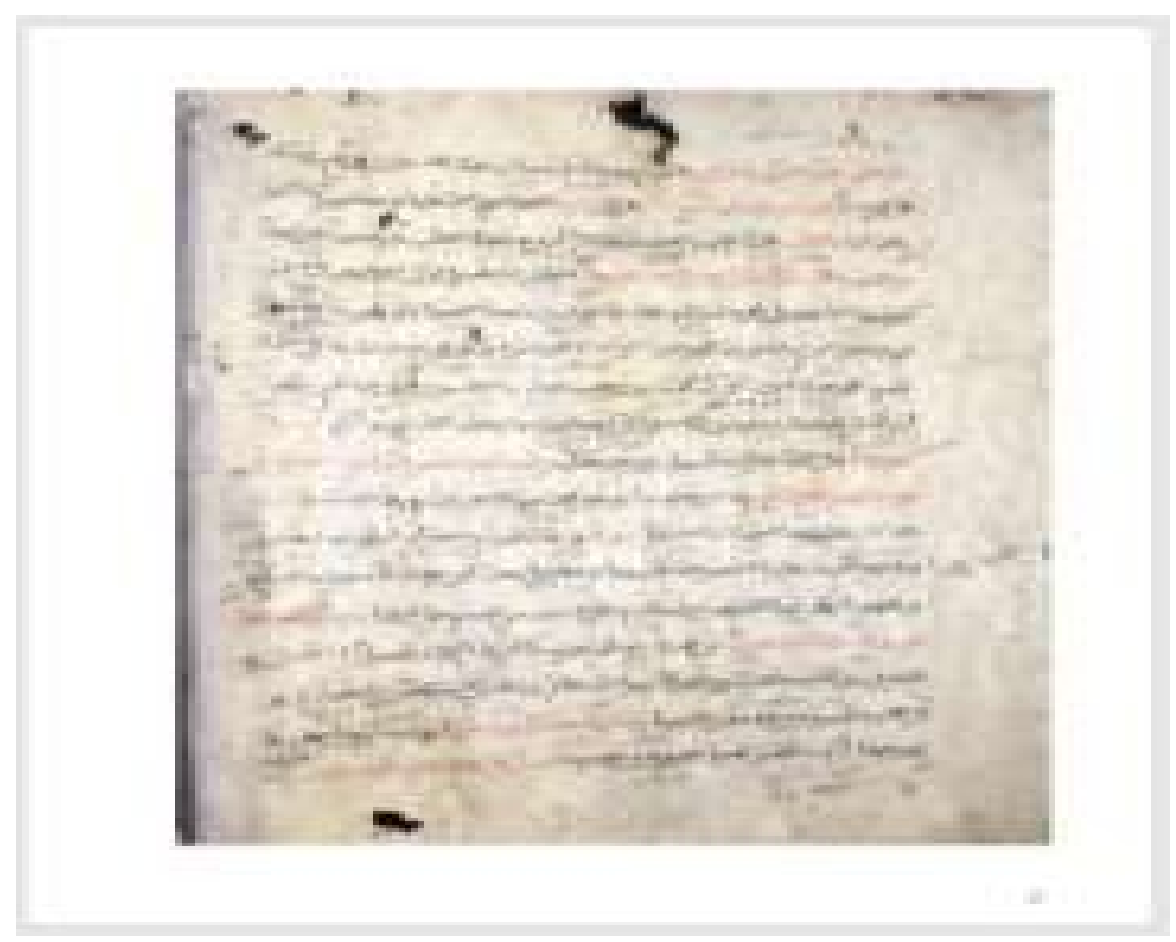

Gambar 4 Tampilan file naskah kuno dalam bentuk microsoft word A-5

\section{KESIMPULAN}

Digitalisasi naskah kuno yang terdapat di Museum Bandar Cimanuk, Indramayu, merupakan upaya pengembangan dan pelestarian warisan budaya sebagai identitas diri dari kota Indramayu. Prioritas yang ditetapkan oleh Museum Bandar Cimanuk, Indramayu dalam melakukan kegitan digitalisasi tergantung dari faktor-faktor seperti, nilai bahan pustaka yang dimiliki, jenis bahan pustaka dan kebutuhan pengguna jasa museum. Dalam melakukan kegiatan digitalisasi naskah kuno di Museum Bandar Cimanuk, Indramayu, terdapat sejumlah tahapan yang harus dilakukan yaitu tahapan pradigitalisasi dan tahapan pengorganisasian. Pemerintah dan masyarakat adat harus sudah memiliki suatu perencanaan strategis atau roadmap yang jelas, tegas, dan menyeluruh sehingga upaya pelestarian dari naskah kuno yang terdapat pada Museum Bandar Cimanuk, Indramayu dapat dinikmati oleh stakeholder. 


\section{DAFTAR PUSTAKA}

Agrawal, R., Gupta, A., \& Sarawagi, S. (1997). Modeling multidimensional databases. 232-243.

Ahmed, F. (2009). Digitization as a Means of Preservation of Manuscripts: Case study of Osmania University Library. Journal Pondicherry University, 94.

Barried, S. B. (1985). Pengantar Teori Filologi. Pusat Pembinaan dan Penggunaan Bahasa.

Djamaris, E. (2002). Pengantar Sastra Rakyat Minangkabau. Yayasan Obor Indonesia.

Gandhi, I. R. (2017). A Study towards Ancient and Modern Presrevation Techniques of Historical Manuscripts against Deterioration. Bharath University Volume 6, Issue 4, Jully- Agustust 2017, 8-10.

Indonesia, K. B. B. (2011). Jakarta. Republik Indonesia.

Kummar, S. L. (2004). Digital Preservation of Manuscripts : A Case Study. IFLIBNET Centre, Ahmedabad, 27.

Lee, S. D. (2001). Digital Imaging: A Practical Hand Book. Neal-Schuman Publishers.

Putranto, M. T. D. (2015). PROSES DIGITALISASI KOLEKSI DEPOSIT DI UPT PERPUSTAKAAN DAERAH PROVINSI JAWA TENGAH. Jurnal Ilmu Perpustakaan, 4(3), 161-170. https://ejournal3.undip.ac.id/index.php/jip/article/view/9736

Sukaesih, S., Winoto, Y., Rusmana, A., \& Kurniasih, N. (2016). Preservation of Ancient Manuscripts as Effort Building Knowledge Management (The study of ancient manuscripts preservation activities by the public as efforts to build knowledge management). Record and Library Journal, 2(2), 176-187.

Tajuddin, M. H. (2018). Preservasi Naskah Kuno Sasak Lombok Berbasis Digital dan Website. Jurnal Teknologi Informasi dan Ilmu Komputer Vol. 5 No. 4, September 2018, 446-450. 